\title{
Physiotherapy in Liver Transplantation
}

\author{
Meriç Şenduran ${ }^{1}$ and S. Ufuk Yurdalan ${ }^{2}$ \\ ${ }^{1}$ Dokuz Eylul University / School of PTR \\ ${ }^{2}$ Marmara University/ Health Sciences Faculty / Department of PTR \\ Turkey
}

\section{Introduction}

Liver transplantation is the definite surgical treatment for patients with end-stage liver disease and acute liver failure that improves liver functions and survival. In recent years health-related quality of life has been accepted to be in relation with surgical success and has become to be used as an important assessment parameter not only after transplantation but also during the disease process.

The most limited sub-group of quality of life is probably the physical activity level that is reduced due to low physical performance status both before and after liver transplantation. This limitation is multi-factorial depending on the stage of the disease and post-transplant period.

Rehabilitative approaches may help patients with liver disease and transplant recipients to improve quality of life by increasing muscle strength, prevent excessive fatigue, enhance aerobic capacity and increase physical activity level. In accordance with this purpose, specific physiotherapeutic interventions structured according to patients' needs in any phase of the disease process should be properly defined by the professions working in related fields.

Physiotherapy in patients with liver disease and liver transplant recipients could mainly be divided into three periods: Pre-operative physiotherapy, early post-operative physiotherapy and late post-operative physiotherapy. A similar rehabilitation process including six different periods after orthotopic liver transplantation has been previously defined as follows: pre-operative period, early and late post-operative periods, early and late ambulatory care periods and motor rehabilitation (Rongies et al., 2005).

In any period of physiotherapy, indications and contraindications for participation in this long rehabilitation process should be well-clarified. Any sign of acute rejection of the transplanted organ, acute hemorrhage, electrolyte imbalance, physiological instability, severe neurologic complications and severe cardiovascular co-morbidities may further effect the implementation of specific techniques and exercises. Therefore phase-dependent specialized assessment procedures should be carried out before planning the exercise programs. Physiotherapeutic evaluation should include the assessment of muscle strength and endurance, aerobic capacity, physical activity level, independency in daily life activities and health-related quality of life. Neurologic, metabolic or musculoskeletal co-morbidities, 
level of pain and fatigue, smoking and alcohol habits should also be recorded within the context of the assessment procedure.

\section{Pre-operative physiotherapy}

Patients waiting on transplantation list with end-stage liver disease usually show loss of muscle mass, low bone mineral density, reduced muscle strength, increased levels of fatigue and decreased aerobic capacity. Malnutrition, cardiopulmonary dysfunction, altered metabolism and corticosteroid treatment are thought to be responsible for the factors that play a role in impaired physical performance.

Diminished exercise capacity is correlated with disease severity in patients with end stage liver disease and is mainly the result of muscle wasting called "cirrhotic myopathy" and cardiac dysfunction called as "cirrhotic cardiomyopathy" (Scott et al., 1998).

Malnutrition is another important factor affecting muscle mass and the activity level. Dysfunctions of glycogen storage and gluconeogenesis in end-stage liver disease lead to a break down of muscle protein and fat for energy usage resulting in weight loss and muscle weakness (Vintro et al., 2002). Poor dietary intake, loss of appetite and medical dietary restrictions may aggravate the secondary effects of malnutrition. In addition to decreased muscle strength and fatigue, severe edema and ascites accompanying the disease negatively affect the ambulation leading to decreases in physical activity and performance level.

Stage dependent reduction in aerobic physical fitness, isokinetic muscle strength and health-related quality of life were found in patients with cirrhosis waiting on the transplantation list (Wiesinger et al., 2001). Similarly, two thirds of cirrhotics, without cardiopulmonary disease or other confounding factors displayed significantly reduced aerobic capacity measured by maximal cardiopulmonary exercise testing (Epstein et al., 1998).

All the data revealed from the published papers emphasize the reasonable needs for specific exercise and rehabilitation programs with the objectives of increasing muscle strength and endurance, aerobic capacity and optimizing daily life independency and health-related quality of life by improving physical functioning for the patients waiting on the liver transplantation list. Longer waiting times make the process more difficult. Therefore, strategies for avoiding prolonged bed rest and increasing activity level are recommended as the disease progresses. To start physiotherapeutic interventions before the transplantation will no doubtfully help the patient to overcome post-operative complications and further deconditioning due to inactivity.

\section{Early post-operative physiotherapy}

\subsection{Physiotherapy in the Intensive Care Unit}

Bed rest is a common prescription in the intensive care unit (ICU) because of drainage tubes, arterial lines, urinary and naso-gastric catheters and sometimes as a result of prolonged mechanical ventilation. Although bed rest can be considered as a part of the treatment in the ICU, immobilization may further affect the overall health status as a consequence of muscle atrophy, diminished bronchial drainage and decreased lung expansion. Physiotherapy in 
the ICU aims to avoid complications of immobilization, provide respiratory support in order to prevent post-operative pulmonary complications and restore functional independency (Stiller, 2000). Post-operative pulmonary complications are common in patients who have undergone open abdominal surgery (Pasquina et al., 2006; Browning et al., 2007). Decreased mucociliary activity due to anesthesia and relatively longer surgery durations and immobilization during the operation may lead to dysfunction of the respiratory system and an increase in bronchial secretion. Post-operative pain resulting from an extensive surgical incision on the upper abdominal region negatively affects coughing by inhibiting the required contraction of abdominal muscles. Pain may also inhibit the physical activities of the patient not only for mobilization but also in bed during supine position. Therefore, it is important to implement effective analgesic treatment in order to overcome post-operative pain and provide bronchial clearance by facilitating coughing mechanism and promoting activity. Diaphragmatic dysfunction is another important factor in the development of pulmonary complications resulting from both pain due to incision and phrenic nerve irritation or paralysis in rare cases.

Early post-transplant physiotherapy including interventions of pulmonary physiotherapy and early mobilization starts on the first post-operative day as soon as the patient is physiologically stabilized and lasts till the patient is discharged from the ICU. Pulmonary physiotherapy including lung expansion and diaphragmatic breathing exercises, forced expiratory technique and coughing techniques and incentive spirometry aims to provide airway clearance, increase lung expansion, restore respiratory function and prevent postoperative pulmonary complications (Clini \& Ambrosino, 2005). Manual techniques including chest percussion and vibration may also be alternative treatment approaches if airway clearance is not accomplished enough although they are not much preferable after a major surgery in the presence of numerous drains. They may also cause the patient to experience more pain and anxiety. Pulmonary physiotherapy should start on the first postoperative day if the patient is already extubated just after the surgery. Unless the patient is extubated in the ICU, a physiotherapist can help to speed the weaning period up as long as the patient is cooperative enough to follow the instructions and participate in the exercises.

Activity after surgery should start as early as possible as the physiological and hemodynamic stabilities are provided. It is important to consider the cardiac and respiratory reserves of the patient and hemoglobin level as well before planning the mobilization session. Mobilization should be implemented gradually as follows in order to be welltolerated by the patient: Limb exercises in supine position, sitting in bed, sitting on the edge of the bed, standing, preparatory walking exercises and ambulation (Senduran et al., 2010). Active-assistive or active limb exercises performed in bed and in sitting position on the edge of the bed stimulate circulation and respiration and should be implemented under supervision during the ICU admission. Lower limb exercises should not cause abdominal pain by increasing the tension on the abdominal region. Therefore, hip movements, especially flexion, should be performed in limited angles. Avoiding abdominal tension during all the activities including sitting and ambulation is necessary to motivate the patient to be more active. In order to prepare the patient for mobilization in the ICU, the surgical area should be bandaged tightly and drains, urine catheter, naso-gastric catheter should be fixed to the body of the patient with a plaster. Additionally, oxygen tube and catheter lines should be lengthened, if necessary. 
Mechanical ventilation and ICU admission are standard post-operative care after liver transplantation improving post-operative outcomes by reducing physiological stress triggered by awakening and spontaneous ventilation (Mandell et al., 2002). However, early extubation is the key element to reduce health care costs by decreasing ICU stay and speed up the patients' recovery. The importance of early extubation, aggressive chest physiotherapy and early ambulation for shortening ICU stay and preventing septic complications and mortality after liver transplantation was highlighted (Mor et al., 2001). Similarly, the vitality of physiotherapy in the ICU after liver transplantation in order to recover muscle waste due to metabolic and nutritional deficits, peripheral neuropathies depending on postural components and respiratory complications was emphasized in another study (Faenza et al., 2005).

The time of physiotherapy initiation after liver transplantation and affecting factors were studied before. A significant correlation between the time of physiotherapy initiation and primary cause of liver transplantation was revealed. Patients with acute liver failure were the latest group that was enrolled in early post-operative physiotherapy suggesting the influence of compensation theory for the healing process rather than a rapid disease progression. A strong relationship between the time of initiation and the ability to take fully upright position was also detected in the same study (Rongies et al., 2005).

Hemodynamic instability is common early after liver transplantation due to cardiac abnormalities characterized by cirrhosis per se. It is well documented that end stage liver disease is characterized by hyperdynamic circulation leading to higher resting heart rate, increased cardiac output and decreased systemic vascular resistance (Wong et al., 2001). Therefore, ongoing monitoring of vital signs, especially arterial pressures, heart rate, respiratory rate and peripheral oxygen saturation is recommended during the physiotherapy interventions in the ICU in order to observe physiological responses in case of any adverse effects.

\subsection{Physiotherapy in the clinical setting}

Similar interventions should also continue after discharge from the ICU ward and progress according to the patient's health and physical status. Inpatient rehabilitation after liver transplantation also includes chest physiotherapy and active-assisted and active limb exercises in order to overcome post-surgical fatigue and improve physical performance level.

Pulmonary physiotherapy including lung expansion and diaphragmatic breathing exercises, forced expiratory technique and coughing techniques and incentive spirometry should continue until the discharge from the hospital whether significant pulmonary complications exist or not.

Muscular strengthening exercises, stretching exercises and posture exercises should be included in the inpatient exercise program. Strengthening exercises using elastic bands or free weights for upper and lower limbs help to prevent muscle loss and restore decreased muscle strength and endurance. Intensity of the exercises can be set according to 1 maximum repetition protocol. Stretching exercises are used to provide normal muscle elongation, especially in patients suffering from prolonged immobilization that may further affect daily activities and even ambulation. Stretching and posture exercises also help to prepare the patient for the exercise session and may stimulate relaxation and anxiety reduction. 
It is important to increase the independency of self-care activities during the hospital stay. Fatigue is one of the major problems in patients with liver diseases which may be exacerbated in the early post-operative period. Exercises should progress gradually by increasing the number of repetitions, frequency during the day or the intensity according to the patient's general condition.

Studies related to inpatient physiotherapy after liver transplantation is limited in the literature. In a retrospective study, significant functional gains were achieved by acute inpatient rehabilitation in 55 liver transplant recipients. Nevertheless, the details and the content of inpatient rehabilitation that the patients participated in during their hospital stay were not mentioned (Cortazzo et al., 2005).

In another study indicating the long rehabilitation process after liver transplantation early mobilization and exercises with graded intensity were implemented to 38 liver transplant recipients during post-operative three weeks and progressed to strengthening, balance, flexibility and aerobic exercises after the third post-transplant week. Exercise treatment continued as one hour in two weeks after the discharge and lasted for 8-24 weeks. As a result of the rehabilitation process significant improvements in aerobic capacity, muscle strength and physical performance were reported (Beyer et al., 1999).

Patient education is another important part of inpatient rehabilitation especially during the first six weeks. Patients should be warned about not driving, not lifting, pushing or pullling heavy objects and not attempting sit-ups, push-ups or pull-ups.

Inpatient physiotherapy should continue until the patient is discharged from the hospital. Structured, systematic and individualized home exercise programs should be well-planned according to the patients' needs and be followed by regular controls. If there is a possibility for the patients to continue rehabilitation process in a clinical setting, they can enroll in an outpatient rehabilitation process under the supervision of physiotherapists. If outpatient rehabilitation service is not available telerehabilitation may be an alternative choice which is popular in recent days in the rehabilitation field. A simple connection from the patient's house to the clinical setting is required in order to be supervised by the professions.

\section{Late post-operative physiotherapy}

\subsection{Early phase interventions}

Early phase interventions involve the first three months after the discharge from the hospital. A home exercise program which is tailored to the individual patient should be prescribed. A handbook containing simple instructions and illustrations for exercises, suggestions for a more active life style and dietary requirements may help the patient after discharge.

The first aim of this period is to maintain the possible highest level of physical activity. Pedometers and accelerometers may be used for not only monitoring but also defining a target daily activity level and will help to motivate the patient to be more active. Patients may develop a fear of damaging the newly transplanted organ and the protective attitudes of the family members may lead to restriction of the activity. Patients should be encouraged to stay more active by the multidisciplinary team including physicians, physiotherapists, dieticians, psychologists, social workers and family members as well. 
During this period the patient may experience anxiety and irritability, sleep disturbances, stress and depression. Optimum level of physical activity and continuing inpatient exercises early after the discharge period will also help the patient to overcome these symptoms.

\subsection{Late phase interventions}

The late post-operative period, that starts mainly three months after liver transplantation aims to provide maximum capacity for daily life independency and optimize health-related quality of life. Returning to job, social life and leisure activities and even returning to sports participation are the objectives of this life-long process. Flexibility, balance, resistance and aerobic exercises are paramount in this period.

Although liver transplantation is the only definite treatment for end-stage liver disease in order to regulate liver functions and maintain survival, it is not a solution per se for restoring the overall health status which is impaired due to loss of muscle mass, excessive fatigue, reduced physical performance and diminished aerobic capacity. Supervised rehabilitation programs are required to improve functional capacity after liver transplantation as surgery alone has a very modest and inconsistent effect on aerobic capacity (Lemzye et al., 2010). Studies investigating the level of aerobic capacity by measuring maximal oxygen uptake after liver transplantation found significant improvements in the long term process. In a related study functional capacity improved 12 months after transplantation compared to the pre-operative period whereas no significant difference existed on the $3^{\text {rd }}$ month-measurements (Iscar et al., 2009). In another similar investigation no significant difference was found in terms of isokinetic muscle strength and aerobic capacity before and 1-2 months after orthotopic liver transplantation without any post-operative rehabilitative approaches (Pieber et al., 2006).

Resistance exercises help to restore muscle strength and prevent osteoporosis which may occur due to immunosuppressant therapy. Osteoporosis has been reported as a common cause of morbidity after liver transplantation leading to bone fractures especially in the first six months after the surgery (Atamaz et al., 2006). Aerobic training consisted of walking; jogging or cycling should also be planned in accordance with cardiac and pulmonary reserve of each patient. Physical activity level, co-morbidities, level of fatigue, and any complication should be considered while planning the exercise regimens. Treadmill and cycle ergometers can be alternative training methods to increase aerobic capacity. It was documented that transplant recipients experienced a positive perception of self esteem, body image and well-being after an 8-week structured aerobic exercise program (Surgit et al., 2001).

It is well-known that life-long immunosuppressive therapy has long-term consequences including not only muscle and bone loss but also cardiovascular risks due to hyperlipidemia and hypertension. Patients will benefit from regular exercise programs to delay the cardiovascular complications. Weight control is another problem during the late postoperative phase as a result of corticosteroids. Combined aerobic and resistance exercise trainings will no doubtfully help the patient to control excessive weight gain. A home-based exercise and nutrition behavior modifications initiated early after transplantation including regular follow-ups resulted in significant gains in exercise capacity, quality of life and body composition (Krasnoff et al., 2006). 
Post-transplant rehabilitation programs are also suggested for reducing the complaint of physical fatigue which remains as one of the most distressing symptoms even one year after the surgery leading to a sedentary lifestyle (Van der Ber-Emons et al., 2006). Muscle energy techniques and interval trainings will provide energy saving and avoid excessive fatigue.

\subsection{Sports participation}

Sports participation after solid organ transplantation is the final objection of the long term rehabilitation process for maximizing quality of life. It is recommended to encourage the patients to participate in a sports activity three months after the surgery. This time is required to achieve optimal flexibility, muscular strength, muscular endurance and aerobic capacity and to provide proper post-operative wound healing and graft stabilization so that the patient can do sports without any deterioration. Patients should start with light activities such as walking, stair climbing, golf, bowling, darts, archery and fishing. Table tennis and volleyball can be suggested as medium intensity activities. Swimming, athletics, badminton, cycling, rowing, squashes, tennis, mini-marathon are recommended after getting used to light and moderate activities. However, swimming in community pools or lakes is not recommended because of high risk of infectious organisms. High impact and contact sports such as football, basketball, horse riding and bungee jumping are not preferable as they may cause a serious trauma and lead to organ damage. Patients usually have a fear of organ damage or severe pain avoiding them to participate in sports. Contact sports also have an additional fracture risk for weight bearing bones due to long term osteoporotic effects of corticosteroids. As liver transplantation surgery induces a denervation of the liver and intrahepatic vascular system strenuous exercises may carry a high risk for reduction in portal blood flow due to increased demands of contracting muscles (Ersoz\&Ersoz, 2003). Besides, selected and well-prepared liver transplant recipients were able to participate in mountain trek and tolerate exposure to high altitude similar to healthy subjects after a 6month aerobic training and a hypercaloric diet including sugars, proteins and abundant hydration (Pirenne et al., 2004).

Feeling of distress, muscle and joint pain, incisional pain and fatigue are the complaints of transplant recipients during or after exercises. Running, skiing, bike riding and tennis, shotput and body-building were reported as the most popular sports among a group of patients with liver and kidney transplantation (Pupkal et al., 2008).

Patients may participate in a sport not only for a leisure time activity but also for professional competitions. The World Transplant Games Federation, officially recognized by the International Olympic Committee, is a world-wide organization staging international sporting events for transplant athletes for over 20 years in order to demonstrate the ability of sports participation after organ transplantation and to raise awareness of the vitality of organ donation.

\section{Conclusion}

In summary structured, specific and well-planned physiotherapeutic interventions tailored to individual needs of each patient are required before and after liver transplantation in order to prevent muscle and bone loss, delay cardiovascular complications and compete with excessive physical fatigue. Specific exercise programs will increase muscle strength and 
endurance, enhance aerobic capacity, maximize physical activity level and optimize healthrelated quality of life. Exercise programs accompanying dietary counseling will also help the patient to control excessive weight gain. Secondary positive effects of regular exercise on sleep disturbances, depression and anxiety may also be beneficial for liver transplant recipients.

It is possible to divide physiotherapeutic interventions mainly into three periods: preoperative, early post-operative and late post-operative periods. These interventions should be initiated according to individual functional status while the patient is on the waiting list in order to speed up the patient's recovery during the post-transplant period.

An active style should be promoted during the whole life of the transplant recipient. Patients should also be encouraged to participate in sports activity, even on a professional level.

\section{References}

Atamaz, F; Hepguler, S; Karasu, Z; Kilic, M \& Tokat, Y. (2006). The prevention of bone fractures after liver transplantation: Experience with Alendronate treatment. Transpl Proc Vol.38:1448-1452.

Beyer, N; Aadahl, M; Strange, B; Kirkegaard, P; Hansen, BA; Mohr, T \& Kjaer, M. (1999). Improved physical performance after orthotopic liver transplantation. Liver Transpl Surg Vol.5, No. 4 (July):301-309.

Browning, L; Denehy, L \& Scholes, RL. (2007). The quantity of early upright mobilization performed following upper abdominal surgery is low: an observational study. Aust J Physiother Vol 53:47-52.

Clini, E \& Ambrosino, N. (2005). Early physiotherapy in the respiratory intensive care unit. Resp Med Vol.99:1096-1104.

Cortazzo, MH; Helkowski, W; Pippin, B; Boninger, ML \& Zafonte, R. (2005). Acute inpatient rehabilitation of 55 patients after liver transplantation. Am J Phys Med Rehabil Vol.84:880-884.

Epstein, SK; Ciubotaru, RL; Zilberberg, MD; Kaplan, LM; Jacoby, C; Freeman, R \& Kaplan, MM. (1998). Analysis of impaired exercise capacity in patients with cirrhosis. Dig Dis Sci Vol.43, No.8 (August):1701-1707.

Ersoz, G \& Ersoz, S. (2003). Changes in portal blood flow following acute exercise in liver transplant recipients. Transpl Proc Vol.35:1456-1457.

Faenza, S; Bernardi, E; Cuppini, F; Gatta, A; Lauro, A; Mancini, E; Petrini, F; Pierucci, E; Sangiorgi, G; Santoro, A; Varotti, G \& Pinna, A. (2005). Intensive care complications in liver and multivisceral transplantation. Transpl Proc Vol.37:2618-2621.

Iscar, M; Montoliu, MA; Ortega, T; Rodriguez, M; Glez-Pinto, I \& Alonso, P. (2009). Functional capacity before and after liver transplantation. Transpl Proc Vol.41:10141015.

Krasnoff, JB; Vintro, AQ; Ascher, NL; Bass, NM; Paul, SM; Dodd, MJ \& Painter, PL. (2006). A randomized trial of exercise and dietary counseling after liver transplantation. Am J of Transpl Vol.6:1896-1905.

Lemzye, M; Dharancy, S; Neviere, R; Pruvot, FR; Declerck, N \& Wallaert, B. (2010). Aerobic capacity in patients with chronic liver disease: Very modest effect of liver transplantation. Presse Med Vol.39:174-181. 
Mandell, MS; Lezotte, D; Kam, I \& Zamudio, S. (2002). Reduced use of intensive care after liver transplantation: Influence of early extubation. Liver Transpl Vol.8, No.8 (August):676-681.

Mor, E; Cohen, J; Erez, E; Grozovsky, A; Shaharabani, E; Bar- Nathan, N; Yussim, A; Micowiz, R; Shapira, Z \& Zinger, P. (2001). Short intensive care unit stay reduces septic complications and improves outcome after liver transplantation. Transpl Proc Vol.33:2939-2940.

Pasquina, WP; Tramer, MR; Grainer, J \& Bernhard, W. (2006). Respiratory physiotherapy to prevent pulmonary complications after abdominal surgery. Chest Vol.130, No.6 (December):1887-1899.

Pieber, K; Crevenna, R; Nuhr, MJ; Quittan, M; Peck-Radosavljevic, M; Fialka-Moser, V \& Wiesinger, GF. (2006). Aerobic capacity, muscle strength and health-related quality of life before and after orthotopic liver transplantation: Preliminary data of an Austrian transplantation centre. J Rehabil Med Vol.38:322-328.

Pirenne, J; Gelder, VF; Kharkevitch, T; Nevens, F; Verslype, C; Peetermans, WE; Kitade, H; Vanhees, L; Devos, Y; Hauser, M; Hamoir, E; Noizat-Pirenne, F \& Pirotte, B. (2004). Tolerance of liver transplant patients to strenuous physical activity in high-altitude. Am J Transpl Vol.4:554-560.

Pupka, A; Płonek, T; Lewicki, K \& Maroszyk, J. (2008). Influence of physical activity on the health condition of people after organ transplantation. Med Sport Vol.12, No.4:142145.

Rongies, W; Stepniewska, S; Perzynska, EP; Dolecki, W; Wojtaszek, M; OldakowskaJedynak, U; Pawlak, J \& Krawczyk, M. (2005). Rehabilitation principles in patients after orthotopic liver transplantation. EEC Hepatology Vol.1, No.1:41-44.

Rongies, W; Stepniewska, S; Golinska, B; Wojtazsek, M; Dolecki, W; Lewandowska, M; Bialoszewski, D \& Krawczyk, M. (2008). An attempt to assess the influence of primary disease on the results of therapeutic rehabilitation in an early postoperative period in orthotopic liver transplant recipients. Ann Transplant Vol.13, No.1:40-43.

Senduran, M; Yurdalan, SU; Karadibak, D \& Günerli, A. (2010). Haemodynamic effects of physiotherapy programme in intensive care unit after liver transplantation. Disabil Rehabil Vol.32, No.17:1461-6.

Stiller, K. (2000). Physiotherapy in intensive care. Towards an evidence-based practice. Chest Vol.118:1801-13.

Surgit, O; Ersoz, G; Gursel, Y \& Ersoz, S. (2001). Effects of exercise training on specific immune parameters in transplant recipients. Transpl Proc Vol.33:3298.

Van den Berg-Emons, R; Van Ginneken, B; Wijffels, M; Tilanus, H; Metselaar, H; Stam, H \& Kazemier, G. (2006). Fatigue is a major problem after liver transplantation. Liver Transpl Vol.12:928-933.

Van den Berg-Emons, R; Kazemier, G; Van Ginneken, B; Nieuwenhuijsen, C; Tilanus, H \& Stam, H. (2006). Fatigue, level of everyday physical activity and quality of life after liver transplantation. J Rehabil Med Vol.38:124-129.

Vintro, AQ; Krasnoff, JB \& Painter, P. (2002). Roles of nutrition and physical activity in musculoskeletal complications before and after liver transplantation. AACN Clin Issues Vol.13, No.2:333-47. 
Wiesinger, GF; Quittan, M; Zimmermann, K; Nuhr, M; Wichlas, M; Bodingbauer, M; Asari, R; Berlakovich, G; Crevenna, R; Fialka-Moser, V \& Peck-Radosavljevic, M. (2001). Physical performance and health-related quality of life in men on a liver transplantation waiting list. J Rehabil Med Vol.33:260-265.

Wong, F; Girgrah, N; Graba, J; Allidina, Y; Liu, P \& Blendis, L. (2001). The cardiac response to exercise in cirrhosis. Gut Vol.49:268-275. 


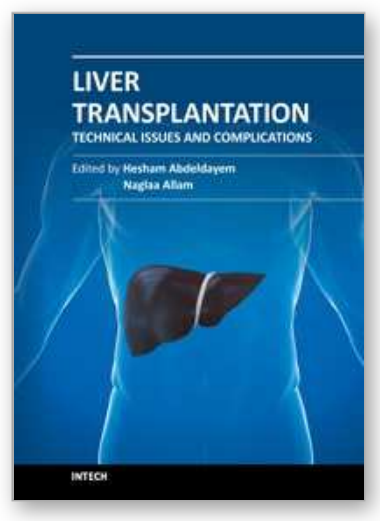

\author{
Liver Transplantation - Technical Issues and Complications \\ Edited by Prof. Hesham Abdeldayem
}

ISBN 978-953-51-0015-7

Hard cover, 454 pages

Publisher InTech

Published online 10, February, 2012

Published in print edition February, 2012

This book covers a wide spectrum of topics including, but not limited to, the technical issues in living and deceased donor liver transplant procedures, cell and experimental liver transplantation, and the complications of liver transplantation. Some of the very important topics, such as the arterial reconstruction in living donor liver transplantation, biliary complications, and the post-transplant-lymphoprolifrative disorders (PTLD), have been covered in more than one chapter.

\title{
How to reference
}

In order to correctly reference this scholarly work, feel free to copy and paste the following:

Meric Senduran and Ufuk Yurdalan (2012). Physiotherapy in Liver Transplantation, Liver Transplantation Technical Issues and Complications, Prof. Hesham Abdeldayem (Ed.), ISBN: 978-953-51-0015-7, InTech,

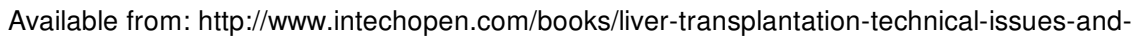
complications/physiotherapy-in-liver-transplantation

\section{INTECH}

open science | open minds

\section{InTech Europe}

University Campus STeP Ri

Slavka Krautzeka 83/A

51000 Rijeka, Croatia

Phone: +385 (51) 770447

Fax: +385 (51) 686166

www.intechopen.com

\section{InTech China}

Unit 405, Office Block, Hotel Equatorial Shanghai

No.65, Yan An Road (West), Shanghai, 200040, China

中国上海市延安西路65号上海国际贵都大饭店办公楼 405 单元

Phone: +86-21-62489820

Fax: $+86-21-62489821$ 
(C) 2012 The Author(s). Licensee IntechOpen. This is an open access article distributed under the terms of the Creative Commons Attribution 3.0 License, which permits unrestricted use, distribution, and reproduction in any medium, provided the original work is properly cited. 